Article

\title{
Acidic Gases Solubility in Bis(2-Ethylhexyl) Sulfosuccinate Based Ionic Liquids Using the Predictive Thermodynamic Model
}

\author{
Amal Mechergui ${ }^{1}$, Alsu I. Akhmetshina ${ }^{1}$, Olga V. Kazarina ${ }^{1}{ }^{\mathbb{D}}$, Maria E. Atlaskina ${ }^{1}$, \\ Anton N. Petukhov ${ }^{1}$ and Ilya V. Vorotyntsev ${ }^{1,2, *(D)}$ \\ 1 Laboratory of Membrane and Catalytic Processes, Nizhny Novgorod State Technical University n.a. R.E. \\ Alekseev, 24 Minina str., Nizhny Novgorod 603950, Russia; amalfatroucha@gmail.com (A.M.); \\ aai-89@mail.ru (A.I.A.); olga_kazarina@list.ru (O.V.K.); m.e_salnikova@mail.ru (M.E.A.); \\ fox_off@mail.ru (A.N.P.) \\ 2 SMART PolyMaT Key Laboratory, D. Mendeleev University of Chemical Technology of Russia, \\ Miusskaya Sq. 9, Moscow 125047, Russia \\ * Correspondence: ilyavorotyntsev@gmail.com; Tel.: +7-920-060-9030
}

Received: 29 February 2020; Accepted: 14 December 2020; Published: 16 December 2020

\begin{abstract}
To properly design ionic liquids (ILs) adopted for gases separation uses, a knowledge of ILs thermodynamic properties as well their solubilities with the gases is essential. In the present article, solubilities of $\mathrm{CO}_{2}$ and $\mathrm{H}_{2} \mathrm{~S}$ in bis(2-Ethylhexyl)sulfosuccinate based ILs were predicted using the conductor like screening model for real solvents COSMO-RS. According to COSMO-RS calculations, the influence of the cation change was extensively analyzed. The obtained data are used for the prediction of adequate solvent candidates. Moreover, to understand the intrinsic behavior of gases solubility the free volume of the chosen ILs and their molecular interactions with respectively $\mathrm{CO}_{2}$ and $\mathrm{H}_{2} \mathrm{~S}$ were computed. The results suggest that hydrogen bonding interactions in ILs and between ILs and the gases have a pivotal influence on the solubility.
\end{abstract}

Keywords: gas mixtures; ionic liquid membrane; hydrogen sulfide; carbon dioxide; sorption; thermodynamic

\section{Introduction}

Among the current environmental issues, the removal of acidic gases such as carbon dioxide and hydrogen sulfide has received great attention due to the necessity of preventing the greenhouse effect responsible for irreversible climate changes and negative impact on the biosphere. Nowadays, conventional technology for acidic gases removal in the industry is based on the chemisorption process by an aqueous alkanolamine solution, unfortunately not free of some drawbacks including high energy demand during the regeneration of the liquid, solvent loss and degradation [1]. In this regard, the uprising trend of replacing conventional acidic gases separation techniques by the economically viable and energy-effective membrane or membrane assisted technology has been gaining much interest over the last years, also by authors [2-6]. In the field of membrane gas separations, a novel class of membranes composed of ionic liquids (ILs) or their polymeric derivatives has exhibited an excellent promise for acidic gases separations and has overcome the trade-off outlined in the Robeson upper bound [7-9]. The utilization of ILs for gas capture purposes was first investigated by Blanchard et al. [10]. Research efforts $[11,12]$ in this area have been increasing. Designing task-specific ionic liquids by the chemical alteration of the cation or anion such as tethering a specific functional group [13-18] has attracted great interest in the last few years. The possible combinations between the already existing cations and anions result in a large variation of ionic liquids with unique properties. Due to their 
high cost and limited number, the experimental investigation of all possibly existing ILs has become a challenging task. Therefore, a prior screening and design of ionic liquids with different gases absorption capacities using a reliable computational method [19-23] would be of great value for subsequent experimental work. Gaining much attention over the last few years, the conductor-like screening model for real solvents (COSMO-RS) [24-26] has successfully predicted $\mathrm{CO}_{2}$ solubility in a wide range of ionic liquids. This method is based on the quantum chemical description of individual molecules. It only requires universal parameters and element-specific parameters. Thus, COSMO-RS can be considered as an adequate tool for the predictions of ILs thermodynamic properties, their activity coefficients and their Henry's law constants [26-28]. Additionally, the solubility characteristics of some macromolecules and polymers $[29,30]$ in ILs have also been modelled by COSMO-RS. Overall, COSMO-RS can be applied for the calculation of liquid-liquid equilibria and solvent prescreening. In the present work, the solubility of $\mathrm{CO}_{2}$ and $\mathrm{H}_{2} \mathrm{~S}$ in four different ILs (Table 1) has been predicted by COSMO-RS. The effect of the type of the cation and its structural variations on gases solubilities have been examined systematically using extensive computational screening considering the ILs molecular structures.

Table 1. The investigated cations and anion of ionic liquids.

\begin{tabular}{|c|c|c|c|}
\hline Abbreviation & Name & Structure & $\begin{array}{c}\text { Molar } \\
\text { mass } / g / m o l\end{array}$ \\
\hline [bmim] & 1-butyl-3-methylimicazolium cation & & 139.17 \\
\hline$[\mathrm{mim}]$ & 1-methylimidazolium cation & & 83.10 \\
\hline [empyrr] & $\begin{array}{l}\text { 1-ethyl-1-methylpyrrolidinium } \\
\text { cation }\end{array}$ & & 114.21 \\
\hline [hpyr] & 1-hexylpyridinium cation & & 164.21 \\
\hline [doc] & $\begin{array}{c}\text { docusate anion } \\
\text { (bis(2-ethylhexyl) sulfosuccinate, } \\
\text { dioctyl sulfosuccinate (DOSS)) }\end{array}$ & & 421.57 \\
\hline
\end{tabular}

\section{Theory}

\subsection{Theory of Calculation Methods}

Conductor like screening model for real solvents COSMO-RS is a new method for the prediction of thermophysical and chemical properties of fluids and liquid mixtures based on unimolecular quantum chemical calculations [31]. The full description of the methodology can be found elsewhere, and only major features needed for understanding the analysis and the discussion of the obtained results are highlighted here. Each COSMO-RS calculation includes two steps. The first step is the quantum chemical COSMO/DFT calculations of the chosen molecules. During this stage, each entity is individually inserted in a perfect conductor where a cavity is constructed around the molecule so it induces a charge distribution in the discrete surface (the cavity) between the counterion and the conductor. These charges are called screening charges, and the surface density $\sigma$ usually represents them. This charge distribution is considered as the most important molecular descriptor. The obtained screening charge density of individual molecules are converted into the probability distribution function (histogram) $p^{\prime}(\sigma)$ or $\sigma$-profile. The $\sigma$-profile of a mixture $p(\sigma)$ is built by adding the $p^{\prime}(\sigma)$ of the already screened molecules weighted by their mole fractions in the mixture [32]. Having the $\sigma$-profile, the chemical potential is calculated by solving couples of non-linear equations. Finally, the obtained chemical potential is used to calculate thermodynamical properties such as activity 
coefficients, Henry's Law constants, solubilities of liquids and gases in IL etc. The main working equations are given by

The $\sigma$-profile $p(\sigma)$ :

$$
p(\sigma)=\sum_{i} x_{i} p_{i}^{\prime}(\sigma)
$$

The chemical potential:

$$
\mu(\sigma)=-K T \ln \int p\left(\sigma^{\prime}\right) \exp \left\{-\frac{E_{\text {int }}\left(\sigma, \sigma^{\prime}\right)-\mu\left(\sigma^{\prime}\right)}{K T}\right\} \mathrm{d} \sigma^{\prime}
$$

The activity coefficient:

$$
\gamma=\exp \left(\frac{\mu-\mu^{0}}{\mathrm{RT}}\right)
$$

where: $x_{i}$ is the molar fraction of a molecule within a mixture, $E_{\mathrm{int}}$ is the interactions energy, $T$ is the temperature, $K$ is Boltzmann constant and $\mu^{0}$ is the chemical potential at pure state.

\subsection{Computational Details}

Densities, molar volumes and COSMO volumes were obtained for each of the four cation-anions using the COSMOtherm software (Version 3.4). When available, the considered species were directly used from the COSMObase libraries derived from the software provider (COSMOlogic $\mathrm{GmbH}$, Leverkusen, Germany). For those cation and anion species not available within the COSMObases, COSMO files were developed. Optimized structures of cations and anions were designed with TURBOMOLE [32], using the triple- $\zeta$ valence potential (TZVP) basis set [33] with the Becke and Perdew (BP) functional $[34,35]$ at the density functional theory (DFT) level. All COSMO calculations were performed at the TZVP level of theory, consistent with other published works on ILs that have utilized COSMOtherm. Conductor like screening model for real solvents COSMO-RS is a new method for the prediction of thermophysical and chemical properties of fluids and liquid mixtures based on unimolecular.

\subsection{Computational of Fractional Free Volume}

Initially, the free volume was defined as the difference between the molar volume $(\mathrm{Vm})$, and the Van der Waals volume (VVdW) calculated from the Van der Waals radii (rvdW) using the methods and values set proposed by Bondi.

$$
V_{f}=V_{m}-1.3 V_{v d W}
$$

Lately, it has been proven that COSMO radii calculated from the COSMOtherm software are 1.17 times rvdW; therefore, the VVdW can be correlated to COSMO volume VCOSMO which presents the volume enclosed by the COSMO surface or the accessible area of the solvent. As found in the literature and determined by Bara et al., $\mathrm{VCOSMO} \approx 1.3 \mathrm{VVdW}$ thus:

$$
V_{f}=V_{m}-V_{C O S M O}
$$

The fractional free volume $(F F V)$ is defined as the ratio of the space to the occupied space in the considered ILs:

$$
F F V=\frac{V_{m}-V_{\operatorname{COSMO}}}{V_{m}}
$$




\section{Results and Discussions}

\section{1. $\sigma$-Profiles of the Ionic Liquids}

The charge distribution sigma $\sigma$ on the molecular surface can be easily visualized in the histogram function $\sigma$-profile for the investigated ionic liquids which all was with docusate anion ([doc], see Table 2), presented in Figure 1. These graphs of the ILs may be analyzed to understand the ions pair's effects on the ILs properties. Similar to any other ionic liquid, the sigma profiles of [doc] based ILs are qualitatively divided into three regions: hydrogen bond acceptor region for $\sigma>1 \mathrm{e} / \mathrm{nm}^{2}$, hydrogen bond donor region for $\sigma<-1 \mathrm{e} / \mathrm{nm}^{2}$ and the neutral region for the zone in between. The peak around $1.68 \mathrm{e} / \mathrm{nm}^{2}$ at the high polarity zone is assigned to the polar segment in [doc] anion as the distribution charge densities around $0 \mathrm{e} / \mathrm{nm}^{2}$ correspond to the alkyl groups on the anion. In the negative region, we observe peaks at values lower than $-1 \mathrm{e} / \mathrm{nm}^{2}$ which are related to the hydrogen atoms on the [bmim], [mim], [empyrr] and [hpyr] cations capable of acting as potential hydrogen bond donors. Similar to the [doc] anion the sigma distribution between $1 \mathrm{e} / \mathrm{nm}^{2}$ and $-1 \mathrm{e} / \mathrm{nm}^{2}$ are assigned to the nonpolar alkyl groups on the imidazolium, pyrrolidinium and pyridinium rings.

Table 2. The linear regression fits of ionic liquids.

\begin{tabular}{ccc}
\hline ILs & Linear Regression Fit & Correlation Coefficient, $\mathbf{R}$ \\
\hline$[$ mim $][\mathrm{doc}]$ & $\rho$ experimental $=0.743 \rho$ predicted +0.3393 & 1 \\
{$[\mathrm{bmim}][\mathrm{doc}]$} & $\rho$ experimental $=0.7418 \rho$ predicted +0.3338 & 1 \\
\hline
\end{tabular}

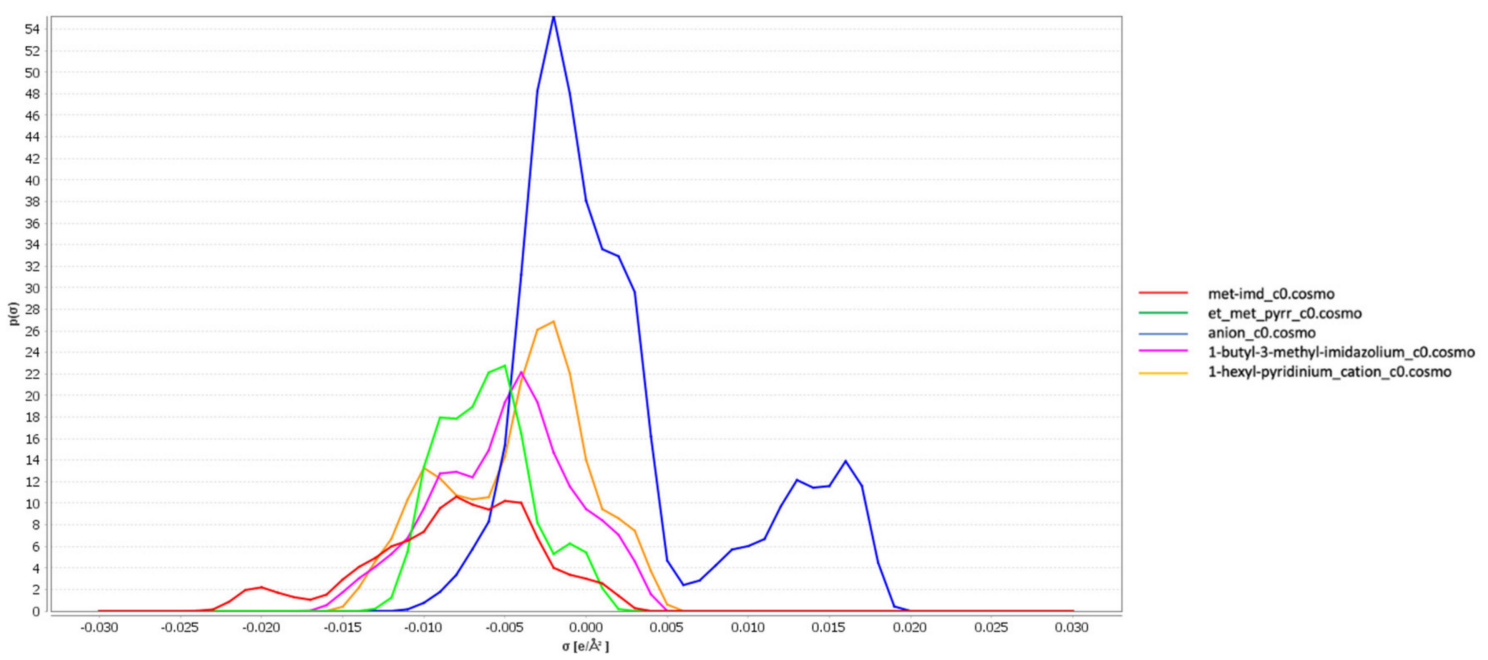

Figure 1. $\sigma$-profiles of docusate based ionic liquids.

\subsection{Screening Charges Densities}

DFT calculations were carried out to visualize the structural variations of the cations on the gases solubility of the studied ILs. As shown in Figure 2, the distribution of the charge on the surface of cations varies considerably for different heterocycles. Two acidic protons $\mathrm{N}(3)-\mathrm{H}$ and $\mathrm{C}(2)-\mathrm{H}$ were observed in the structure of [mim] cation N(3)-H proton acidity was more pronounced. In the case of [bmim] cation, the most acidic site was located in $\mathrm{C}(2)-\mathrm{H}$ bond. The positive charge in the [empyrr] cation was localized in the nitrogen atom, however, on the COSMO-surface the charge was found to be equally distributed because of the presence of alkyl substituents on the nitrogen atom. Finally, $\mathrm{C}(2)-\mathrm{H}$ and $\mathrm{C}(6)-\mathrm{H}$ protons have shown higher acidity than other ones within [hpyr] heterocycle. 


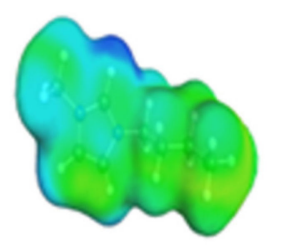

1-butyl-3-methylimidazolium cation

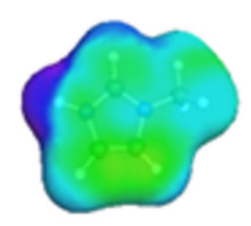

1-methylimidazolium cation

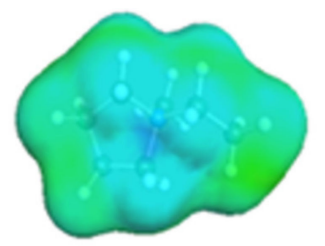

1-ethyl-1-methylpyrrolidinium cation

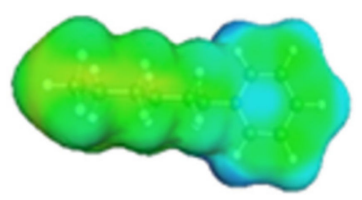

1-hexylpyridinium cation

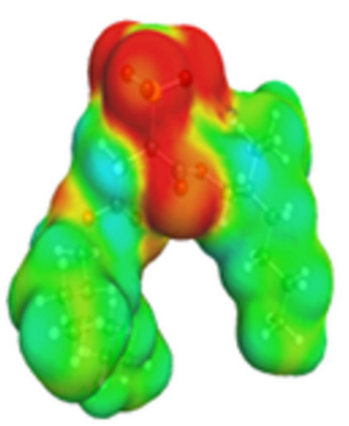

docusate anion

Figure 2. Screening charge $\sigma$ of docusate based ionic liquids.

\subsection{Densities and Volumetric Effects}

The next step was to evaluate the densities of [doc] ILs using the COSMO-RS model. All the predicted densities values are illustrated in Figure 3, with a comparison to the experimental data of the ILs.

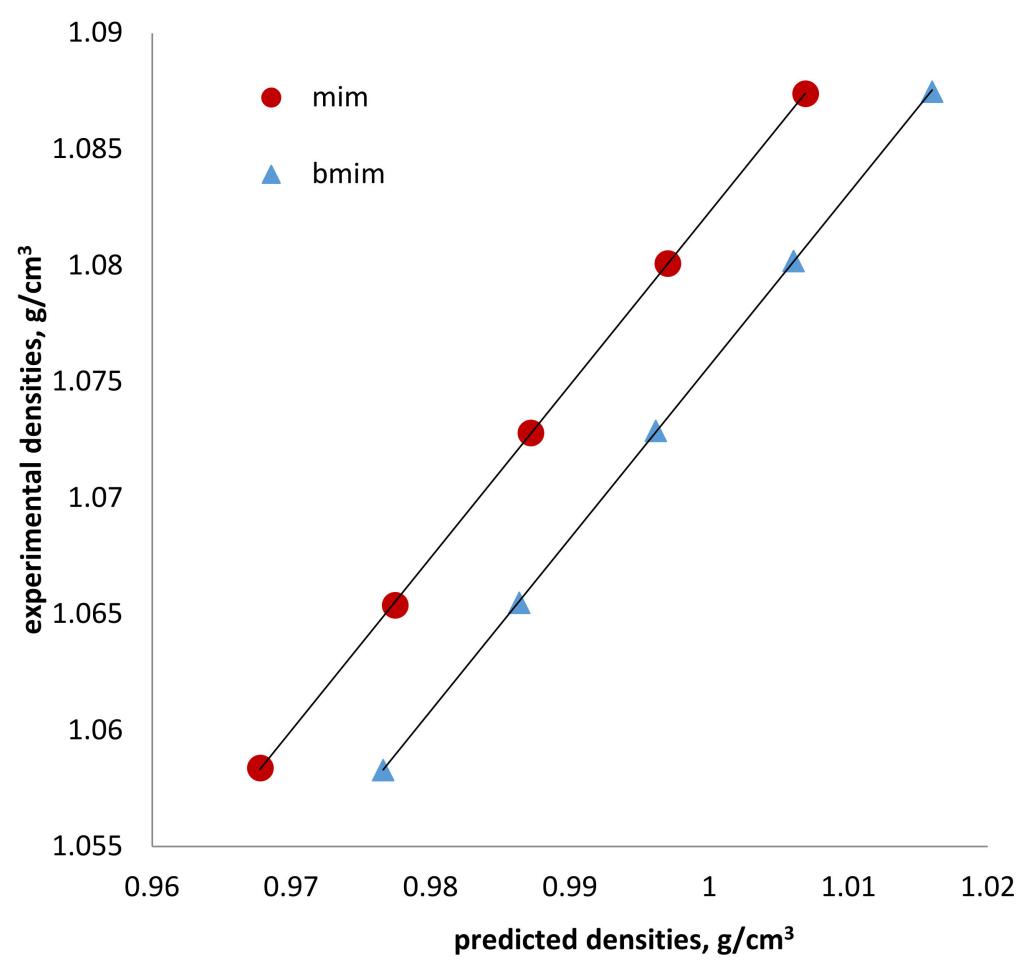

Figure 3. Comparison of experimental and COSMO-RS predicted results of densities $\left(\mathrm{g} / \mathrm{cm}^{3}\right)$ for docusate based ionic liquids.

An excellent linear relationship has been found between the experimental and the calculated densities for all the designed ILs. The linear regression fits represent excellent correlation coefficients $R=1$ as for the slopes they are presented in Table 2. The root means square deviations (rmsd) of 
[bmim][doc], [mim][doc], [empyrr][doc], [hpyr][doc] and some other common ILs are given in Table 3. Although COSMO-RS calculated densities of the organic solvents and the common ILs presented rmsd $<2 \%$ [31], docusate based ILs had higher values. An explanation of such deviation is not evident yet, but this can be related to the structure and the nature of the anion used in this study. It is important to note that the prediction of the ILs densities follows the experimental tendencies related to the cation change effects and the temperature increase [3,36]. Thus, similar to the experimental results, in the case of [mim] [doc] and [bmim][doc] the addition of the alkyl chain on the imidazolium ring resulted in higher densities.

Table 3. COSMO-RS predictions of densities $\rho$ and molar volumes $\left(V_{m}\right) @ 298.15 \mathrm{~K}$.

\begin{tabular}{|c|c|c|c|c|c|c|c|}
\hline \multirow{2}{*}{ ILs } & \multicolumn{2}{|c|}{$\rho\left(\mathrm{g} / \mathrm{cm}^{3}\right)$} & \multirow{2}{*}{ Dev., \% } & \multicolumn{2}{|c|}{$V_{m}\left(\mathrm{~cm}^{3} / \mathrm{mol}\right)$} & \multirow{2}{*}{ Dev., \% } & \multirow{2}{*}{ Reference } \\
\hline & Experim. & Predict. & & Experim. & Predict. & & \\
\hline$[\mathrm{mim}][\mathrm{doc}]$ & 1.084 & 1.017 & 6.59 & 456.587 & 471.762 & 3.32 & [31] \\
\hline$[\mathrm{bmim}][\mathrm{doc}]$ & 1.084 & 1.026 & 5.63 & 506.637 & 546.376 & 7.84 & {$[31]$} \\
\hline [hpyrr][doc] & - & 1.013 & - & - & 575.931 & - & This work \\
\hline [empyrr][doc] & - & 1.069 & - & - & 528.870 & - & This work \\
\hline$[\mathrm{bmim}][\mathrm{BF} 4]$ & 1.205 & 1.194 & 0.90 & 187.824 & 189.028 & 0.64 & [32] \\
\hline$[\mathrm{bmim}]\left[\mathrm{CF}_{3} \mathrm{SO}_{3}\right]$ & 1.301 & 1.319 & 1.40 & 220.934 & 218.526 & 1.09 & [32] \\
\hline$[\mathrm{hxmim}]\left[\mathrm{Tf}_{2} \mathrm{~N}\right]$ & 1.370 & 1.395 & 1.80 & 326.886 & 320.866 & 1.84 & [32] \\
\hline$[\mathrm{emim}]\left[\mathrm{Tf}_{2} \mathrm{~N}\right]$ & 1.521 & 1.531 & 0.65 & 291.970 & 288.358 & 1.24 & [32] \\
\hline
\end{tabular}

Besides, the molar liquid volume was also computed by the model and compared to the experimental presenting an excellent correspondence with each other. Similar to the density, the calculated results computed the same tendency as the experimental results. The densities of ionic liquids were found to increase with the molecular volume, but this is not a general rule. It may prove that the intermolecular interactions in the ILs also govern the physicochemical properties of the ILs.

\subsection{Henry's Law Predictions}

In Table 4 the predicted Henry's law constants of $\mathrm{CO}_{2}$ and $\mathrm{H}_{2} \mathrm{~S}$ in mim[doc], bmim[doc], hpyrr[doc] and empyrr[doc] are reported.

Table 4. Predicted Henry's law constants of $\mathrm{CO}_{2}$ and $\mathrm{H}_{2} \mathrm{~S}$ in the ionic liquids (ILs).

\begin{tabular}{cccccc}
\hline \multirow{2}{*}{ ILs } & \multicolumn{5}{c}{ H(bar) } \\
\cline { 2 - 6 } & $\mathbf{3 0 3 . 1 5} \mathbf{K}$ & $\mathbf{3 1 3 . 1 5} \mathbf{K}$ & $\mathbf{3 2 3 . 1 5} \mathbf{K}$ & $\mathbf{3 3 3 . 1 5} \mathbf{K}$ & $\mathbf{3 4 3 . 1 5} \mathbf{K}$ \\
\hline \multicolumn{5}{c}{$\mathbf{C O}_{\mathbf{2}}$} \\
\hline mim[doc] & 62.694 & 75.498 & 89.712 & 105.323 & 122.303 \\
bmim[doc] & 45.864 & 55.511 & 66.304 & 78.252 & 91.351 \\
hpyrr[doc] & 45.202 & 54.566 & 65.028 & 76.598 & 89.276 \\
empyrr[doc] & 44.107 & 53.610 & 64.301 & 76.199 & 89.309 \\
\hline & 0.721 & 1.0254 & 1.416 & 1.908 & 2.513 \\
\hline mim[doc] & 0.523 & 0.7545 & 1.058 & 1.445 & 1.926 \\
bmim[doc] & 0.528 & 0.760 & 1.061 & 1.445 & 1.923 \\
hpyrr[doc] & 0.461 & 0.673 & 0.953 & 1.315 & 1.771 \\
empyrr[doc] & \multicolumn{7}{c}{$\mathbf{S}$} \\
\hline
\end{tabular}

According to the computed results, structural modifications on the imidazolium ring by the addition of the butyl chain on [mim] cation have increased both $\mathrm{CO}_{2}$ and $\mathrm{H}_{2} \mathrm{~S}$ dissolution in [bmim] [doc]. This observation is in good agreement with K.Z. Sumon et al. (2011) [37] work where the authors have proposed that the increase of the alkyl chain length in ring-precursor enhances $\mathrm{CO}_{2}$ solubility within a given IL. Additionally, similar to K.Z. Sumon et al. work, the solubility of both gases has remarkably 
improved (Henry's law constants decreased) when the cation family has been modified; for both $\mathrm{CO}_{2}$ and $\mathrm{H}_{2} \mathrm{~S}$ the solubility is ranking in the order empyrr[doc] > bmim[doc] > hpyrr[doc] > mim[doc].

Further, bmim [doc] predicted data were compared to those of bmim $\left[\mathrm{BF}_{4}\right]$ and bmim[acetate]. As suggested in the literature [38-40], the anion change has a more pronounced effect on gases solubility. The variation in Henry's law constants when replacing [doc] anion by $\left[\mathrm{BF}_{4}\right]$ and [acetate] anions are larger. The utilization of the docusate anion has enhanced the bmim based ILs sorption capacities for $\mathrm{CO}_{2}$. The bulkier nature and the larger molecular weight of the anion have contributed to this augmentation.

The predicted data has shown that docusate based ILs have a higher affinity towards $\mathrm{H}_{2} \mathrm{~S}$ than $\mathrm{CO}_{2}$. The effects of the alkyl chain modification on the imidazolium-based ILs and the variation of the cation family have been accurately predicted. However, the order of solubility of $\mathrm{CO}_{2}$ and $\mathrm{H}_{2} \mathrm{~S}$ in the ILs computed by COSMOtherm is different from the experimental.

The experimental data on Henry's constants are given also in [3], where it is between two and four times less for the cations [mim] and [bmim], respectively. Such a large difference is apparently realized due to the fact that the experimental data for these substances are given with a sufficiently high water content of $0.3722 \mathrm{wt} \%$ and $0.4835 \mathrm{wt} \%$.

According to COSMO-RS calculations, empyrr[doc] has exhibited the highest $\mathrm{CO}_{2}$ and $\mathrm{H}_{2} \mathrm{~S}$ solubilities, but the experiments suggested that bmim[doc] has the highest solvation capacities for both gases.

\subsection{Interpretation of Molecular Interactions with Sigma Profiles and Sigma Potentials}

In this section, we explore the above trends through the properties of ILs and gas-liquid interactions. As mentioned before, the observed trends of solubilities are results of the molecular interactions first between the anions and the cations in the ILs and secondly between the ILs and the gases upon dissolution. The sigma-profiles of the ILs are used to visualize the effect of structural variations on $\mathrm{CO}_{2}$ and $\mathrm{H}_{2} \mathrm{~S}$ solubilities. As for the corresponding $\sigma$-potentials, they can be utilized to ascertain the affinity of the ILs towards the gases.

Almost all the $\sigma$-profiles of the four ILs extended between $-25 \mathrm{e} / \mathrm{nm}^{2}$ and $20 \mathrm{e} / \mathrm{nm}^{2}$. All the ILs sigma-profiles have exhibited similarities in the region around $5-20 \mathrm{e} / \mathrm{nm}^{2}$ owing to the docusate presence being the commonly used anion in the designed ILs. The main difference between the histograms of the ILs is observed in the negative region or precisely in the hydrogen bonding donor region. As concluded from Henry's law constants values the docusate based ILs have a better affinity towards $\mathrm{H}_{2} \mathrm{~S}$ than $\mathrm{CO}_{2}$. When comparing the $\sigma$-profiles of both gases, it is obvious that $\mathrm{CO}_{2}$ is more localized in the neutral region whereas $\mathrm{H}_{2} \mathrm{~S}$ histogram extends beyond both negative and positive regions proving the stronger ability of $\mathrm{H}_{2} \mathrm{~S}$ to interact with the ILs via hydrogen bonding. bmim[doc] has exhibited higher solubilities for both gases than mim[doc]. Although bmim[doc] $\sigma$-profile presents more nonpolar surfaces around $\sigma 0 \mathrm{e} / \mathrm{nm}^{2}$ (which is favorable for $\mathrm{CO}_{2}$ solubility in the IL), the histogram of $\operatorname{mim}$ [doc] extends further in the negative region suggesting a stronger hydrogen bonding donor ability than the rest of the ILs. The fact that $\mathrm{mim}[\mathrm{doc}]$ exhibited lower gases solubilities despite having more negative surface pieces ready to interact with $\mathrm{CO}_{2}$ and $\mathrm{H}_{2} \mathrm{~S}$ is due to the protic nature of [mim] cation containing the weak protonated nitrogen in the imidazolium ring resulting in strong hydrogen bonding interactions between the [mim] cation and the docusate anion and in different arrangements of them at the molecular level preventing further interactions between the gases and the ions and significantly reducing IL sorption capacity.

\subsection{Free Volume Effects and Interactions Enthalpies}

Many works have used the molar volume of an IL as a tool for understanding the solubility of a gas [33]. Some predictive models have correlated Henry's law constants of different gases with the molar of a solvent through its solubility parameters. The scaled particle theory [41] has proposed that Henry's law constant should be decreased when increasing the molar volume of ILs. Although in 
our case, the relation between Henry's law constants and molar volumes didn't match the correlation mentioned above; [empyrr][doc] with the highest $\mathrm{CO}_{2}$ and $\mathrm{H}_{2} \mathrm{~S}$ solubilities (the lowest Henry's law constants) has lower molar volume than [hpyr][doc] and [bmim][doc]. Instead of correlating Henry's law constants of $\mathrm{CO}_{2}$ and $\mathrm{H}_{2} \mathrm{~S}$ in the ILs with their molar volumes, Bara et al., [42] proposed that the solubility of a gas can be related to the free volume or the fractional free volume of the IL. The free volume $\mathrm{V}_{\mathrm{f}}$ is the growing void space that might exist within the IL.

The obtained free volumes values of docusate based ILs, presented in Table 5, were much higher than those reported in previous works [35,36]. As we mentioned before, due to the nature of the used anion it is much bulkier and delocalized than the commonly used anions and the ones available in COSMOtherm database, and probably some future correction should be included to the software for better predictions when treating similar ionic species. It can be seen from the obtained results that the addition of the butyl to the [mim] cation FFV of [bmim][doc] have increased favoring better solubility of gases in the mentioned IL. Otherwise, the FFV tends almost to follow the same trend as the Henry law's constant, [empyrr][doc] with the lowest Henry law's constant for both $\mathrm{CO}_{2}$ and $\mathrm{H}_{2} \mathrm{~S}$ having had the highest FFV. From the observation of the obtained data, it can be confirmed that there is a link between the molar volume, the free volume and the gases solubilities within the ILs. It can be concluded that higher $\mathrm{CO}_{2}$ and $\mathrm{H}_{2} \mathrm{~S}$ solubilities can be achieved when the molar volume of the IL is minimized while the free volume is increased as in the case of [empyrr][doc].

Table 5. Predictions of free volumes $V_{f}$ and fractional free volumes FFV of ILs @ 298K.

\begin{tabular}{ccc}
\hline $\mathbf{I L s}$ & $\mathbf{V}_{\mathbf{f}}\left(\mathbf{c m}^{\mathbf{3}} \mathbf{/ \mathbf { m o l } )}\right.$ & $\mathbf{F F V}$ \\
\hline mim[doc] & 252.1296811 & 0.536972372 \\
bmim[doc] & 320.5894064 & 0.589633588 \\
hpyrr[doc] & 338.0120416 & 0.589782822 \\
empyrr[doc] & 311.7823921 & 0.592451172 \\
\hline
\end{tabular}

Using the COSMO-RS model excess enthalpies of gas-IL mixtures can be predicted as the sum of different contributions of each component of the mixture as follow

$$
H_{m}^{E}=H_{m}^{E}(\text { misfit })+H_{m}^{E}(H-\text { bonding })+H_{m}^{E}(V d W)
$$

According to the equation above, the predicted solubilities of $\mathrm{CO}_{2}$ and $\mathrm{H}_{2} \mathrm{~S}$ can be analyzed in terms of different gas-solvent interactions contributions to the $H_{m}^{E}$ values of $\mathrm{CO}_{2}-\mathrm{IL}$ and $\mathrm{H}_{2} \mathrm{~S}$-IL systems reported in Table 6.

Table 6. The predicted interaction energy contributions of the ILs @ $298.15 \mathrm{~K}$.

\begin{tabular}{ccccccccc}
\hline \multirow{2}{*}{ ILs } & $\begin{array}{c}\text { Misfit Interactions } \\
\text { Energy } \\
\text { Kcal/mol }\end{array}$ & \multicolumn{2}{c}{$\begin{array}{c}\text { H-Bonding } \\
\text { Interactions Energy } \\
\text { Kcal/mol }\end{array}$} & \multicolumn{2}{c}{$\begin{array}{c}\text { VdW Interactions } \\
\text { Energy } \\
\text { Kcal/mol }\end{array}$} & $\begin{array}{c}\text { Total } H_{m}^{E} \\
\text { Kcal/mol }\end{array}$ \\
\cline { 2 - 9 } & $\mathbf{C O}_{\mathbf{2}}$ & $\mathbf{H}_{\mathbf{2}} \mathbf{S}$ & $\mathbf{C O}_{\mathbf{2}}$ & $\mathbf{H}_{\mathbf{2}} \mathbf{S}$ & $\mathbf{C O}_{\mathbf{2}}$ & $\mathbf{H}_{\mathbf{2}} \mathbf{S}$ & $\mathbf{C O}_{\mathbf{2}}$ & $\mathbf{H}_{\mathbf{2}} \mathbf{S}$ \\
\hline mim[doc] & 1.02556 & 1.11703 & 0 & -0.6868 & -2.89609 & -3.65569 & -1.87053 & -2.08448 \\
bmim[doc] & 1.03132 & 1.12246 & 0 & -0.72946 & -2.88958 & -3.64518 & -1.85827 & -2.1119 \\
hpyrr[doc] & 1.02511 & 1.12872 & 0 & -0.71923 & -2.89069 & -3.65656 & -1.8658 & -2.10608 \\
empyrr[doc] & 1.06730 & 1.12549 & 0 & -0.76074 & -2.86842 & -3.60433 & -1.80113 & -2.09859 \\
\hline
\end{tabular}

The highest solubilities of $\mathrm{H}_{2} \mathrm{~S}$ and $\mathrm{CO}_{2}$ by docusate based ILs are associated with higher exothermicity.

As seen from the obtained energies, $\mathrm{CO}_{2}$ solubility within all the prepared ILs is generated by the Van der Waals forces, misfit representing electrostatic interactions are repulsive for both $\mathrm{CO}_{2}$ and $\mathrm{H}_{2} \mathrm{~S}$ and play a secondary role as for the hydrogen bonding and they are mainly absent for $\mathrm{CO}_{2}$ sorption in the four ILs. In the case of $\mathrm{H}_{2} \mathrm{~S}$, the three types of interactions contribute to the solubility of the gas. 
As the dominant contributions, the Van der Waals interactions are responsible for the exothermicity of $\mathrm{CO}_{2}$-IL and $\mathrm{H}_{2} \mathrm{~S}-\mathrm{IL}$ mixtures and the increasing solubilities of both gases within the designed ILs.

\section{Conclusions}

Several structural and physical parameters of the four ILs were predicted using the COSMO-RS model for better understanding of the influence of the cation change. As expected, the lowest fractional free volume values have corresponded to the highest Henry's constants. The predicted data suggested that empyrr[doc] has the highest $\mathrm{H}_{2} \mathrm{~S}$ and $\mathrm{CO}_{2}$ absorption capacity. This observation can be interpreted by the weaker interactions between the cation and the anion resulting in more available void space within the IL allowing the gases to better with the ionic species in the solvent. In summary, we have proved the applicability of the approach based on the introduction of sterically hindered moieties along with polar functional groups in the anion structure towards the development of $\mathrm{H}_{2} \mathrm{~S}$ and $\mathrm{CO}_{2}$-selective absorbents.

Author Contributions: A.M., A.I.A. performed the theoretical modelling. Gas sorption properties of IL investigation were performed by A.N.P. and I.V.V. Density and viscosity data was obtained by M.E.A. and O.V.K. I.V.V. and A.M. wrote the manuscript. I.V.V. supervised the work and revised the manuscript. All authors have read and agreed to the published version of the manuscript.

Funding: This work was supported by the Council on grants of the President of the Russian Federation (MD-4990.2018.3) and Russian Foundation of Basic Research (19-38-60011) and by the Ministry of Science and Higher Education of the Russian Federation in the Frame-work of the Basic Part of the State Task [project No. FSWE-2020-0008].

Conflicts of Interest: The authors declare no conflict of interest.

\section{Abbreviations}

$\begin{array}{ll}{[\mathrm{doc}]} & \begin{array}{l}\text { bis(2-Ethylhexyl) sulfosuccinate anion } \\ \text { tetrafluoroborate anion }\end{array} \\ {\left[\mathrm{BF}_{4}\right]} & \begin{array}{l}\text { trifluoromethanesulfonate anion } \\ {\left[\mathrm{CF}_{3} \mathrm{SO} 3\right]}\end{array} \\ {\left[\mathrm{Tf}_{2} \mathrm{~N}\right]} & \text { bistriflamide anion } \\ {[\mathrm{bmim}]} & \text { 1-butyl-3-methylimidazolium cation } \\ {[\mathrm{mim}]} & \text { 1-methylimidazolium cation } \\ {[\text { empyrr }]} & \text { 1-ethyl-1-methylpyrrolidinium cation } \\ {[\mathrm{hpyr}]} & \text { 1-hexylpyridinium cation } \\ \mathrm{IL} & \text { ionic liquid } \\ \mathrm{DFT} & \text { density functional theory } \\ \mathrm{rmsd} & \text { root means square deviations }\end{array}$

\section{References}

1. Mokhatab, S.; Poe, W.A.; Speight, J.G. Handbook of Natural Gas Transmission and Processing; Gulf Professional Publishing: Waltham, MA, USA, 2015; p. 261.

2. Akhmetshina, A.I.; Yanbikov, N.R.; Atlaskin, A.A.; Trubyanov, M.M.; Mechergui, A.; Otvagina, K.V.; Razov, E.N.; Mochalova, A.E.; Vorotyntsev, I.V. Acidic gases separation from gas mixtures on the supported ionic liquid membranes providing the facilitated and solution-diffusion transport mechanisms. Membranes 2019, 9, 9. [CrossRef]

3. Akhmetshina, A.I.; Petukhov, A.N.; Gumerova, O.R.; Vorotyntsev, A.V.; Nyuchev, A.V.; Vorotyntsev, I.V. Solubility of $\mathrm{H}_{2} \mathrm{~S}$ and $\mathrm{CO}_{2}$ in imidazolium-based ionic liquids with bis(2-ethylhexyl) sulfosuccinate anion. J. Chem. Thermodyn. 2019, 130, 173-182. [CrossRef]

4. Atlaskin, A.A.; Kryuchkov, S.S.; Yanbikov, N.R.; Smorodin, K.A.; Petukhov, A.N.; Trubyanov, M.M.; Vorotyntsev, V.M.; Vorotyntsev, I.V. Comprehensive experimental study of acid gases removal process by membrane-assisted gas absorption using imidazolium ionic liquids solutions absorbent. Sep. Purif. Technol. 2020, 239, 116578. [CrossRef] 
5. Atlaskin, A.A.; Kryuchkov, S.S.; Smorodin, K.A.; Markov, A.N.; Kazarina, O.V.; Zarubin, D.M.; Atlaskina, M.E.; Vorotyntsev, A.V.; Nyuchev, A.V.; Petukhov, A.N.; et al. Towards the potential of trihexyltetradecylphosphonium indazolide with aprotic heterocyclic ionic liquid as an efficient absorbent for membrane-assisted gas absorption technique for acid gas removal applications. Sep. Purif. Technol. 2020, 257, 117835. [CrossRef]

6. Vorotyntsev, V.M.; Drozdov, P.N.; Vorotyntsev, I.V.; Murav'ev, D.V. Fine gas purification to remove slightly penetrating impurities using a membrane module with a feed reservoir. Dokl. Chem. 2006, 411, 243-245. [CrossRef]

7. Zulfiqar, S.; Sarwar, M.I.; Mecerreyes, D. Polymeric ionic liquids for $\mathrm{CO}_{2}$ capture and separation: Potential, progress and challenges. Polym. Chem. 2015, 6, 6435-6451. [CrossRef]

8. Karkhanechi, H.; Salmani, S.; Asghari, M. A review on gas separation applications of supported ionic liquid membranes. ChemBioEng Rev. 2015, 2, 290-302. [CrossRef]

9. Sanders, D.F.; Smith, Z.P.; Guo, R.; Robeson, L.M.; McGrath, J.E.; Paul, D.R.; Freeman, B.D. Energy-efficient polymeric gas separation membranes for a sustainable future: A review. Polymer 2013, 54, 4729-4761. [CrossRef]

10. Blanchard, L.A.; Hancu, D.; Beckman, E.J.; Brennecke, J.F. Green processing using ionic liquids and $\mathrm{CO}_{2}$. Nature 1999, 399, 28-29. [CrossRef]

11. Lei, Z.; Dai, C.; Chen, B. Gas solubility in ionic liquids. Chem. Rev. 2014, 114, 1289-1326. [CrossRef]

12. Jin, F.; He, L.N.; Hu, Y.H. Advances in $\mathrm{CO}_{2}$ Capture, Sequestration, and Conversion; American Chemical Society: Washington, DC, USA, 2016.

13. Bates, E.D.; Mayton, R.D.; Ntai, I.; Davis, J.H. $\mathrm{CO}_{2}$ capture by a task-specific ionic liquid. J. Am. Chem. Soc. 2002, 124, 926-927. [CrossRef] [PubMed]

14. Galán Sánchez, L.M.; Meindersma, G.W.; de Haan, A.B. Solvent properties of functionalized ionic liquids for $\mathrm{CO}_{2}$ absorption. Chem. Eng. Res. Design 2007, 85, 31-39. [CrossRef]

15. Gutowski, K.E.; Maginn, E.J. Amine-functionalized task-specific ionic liquids: A mechanistic explanation for the dramatic increase in viscosity upon complexation with $\mathrm{CO}_{2}$ from molecular simulation. J. Am. Chem. Soc. 2008, 130, 14690-14704. [CrossRef] [PubMed]

16. Goodrich, B.F.; de la Fuente, J.C.; Gurkan, B.E.; Zadigian, D.J.; Price, E.A.; Huang, Y.; Brennecke, J.F. Experimental measurements of amine-functionalized anion-tethered ionic liquids with carbon dioxide. Ind. Eng. Chem. Res. 2011, 50, 111-118. [CrossRef]

17. Gurkan, B.; Goodrich, B.F.; Mindrup, E.M.; Ficke, L.E.; Massel, M.; Seo, S.; Senftle, T.P.; Wu, H.; Glaser, M.F.; Shah, J.K.; et al. Molecular design of high capacity, low viscosity, chemically tunable ionic liquids for $\mathrm{CO}_{2}$ capture. J. Phys. Chem. Lett. 2010, 1, 3494-3499. [CrossRef]

18. Wang, C.; Luo, H.; Jiang, D.-E.; Li, H.; Dai, S. Carbon dioxide capture by superbase-derived protic ionic liquids. Angew. Chem. Int. Ed. 2010, 49, 5978-5981. [CrossRef] [PubMed]

19. Kim, Y.S.; Choi, W.Y.; Jang, J.H.; Yoo, K.P.; Lee, C.S. Solubility measurement and prediction of carbon dioxide in ionic liquids. Fluid Phase Equilibria 2005, 228-229, 439-445. [CrossRef]

20. Scovazzo, P.; Camper, D.; Kieft, J.; Poshusta, J.; Koval, C.; Noble, R. Regular solution theory and $\mathrm{CO}_{2}$ gas solubility in room-temperature ionic liquids. Ind. Eng. Chem. Res. 2004, 43, 6855-6860. [CrossRef]

21. Eike, D.M.; Brennecke, J.F.; Maginn, E.J. Predicting infinite-dilution activity coefficients of organic solutes in ionic liquids. Ind. Eng. Chem. Res. 2004, 43, 1039-1048. [CrossRef]

22. Kroon, M.C.; Karakatsani, E.K.; Economou, I.G.; Witkamp, G.-J.; Peters, C.J. Modeling of the carbon dioxide solubility in imidazolium-based ionic liquids with the tpc-psaft equation of state. J. Phys. Chem. B 2006, 110, 9262-9269. [CrossRef]

23. Kerlé, D.; Ludwig, R.; Geiger, A.; Paschek, D. Temperature dependence of the solubility of carbon dioxide in imidazolium-based ionic liquids. J. Phys. Chem. B 2009, 113, 12727-12735. [CrossRef] [PubMed]

24. Marsh, K.N.; Boxall, J.A.; Lichtenthaler, R. Room temperature ionic liquids and their mixtures-A review. Fluid Phase Equilibria 2004, 219, 93-98. [CrossRef]

25. Zhang, X.; Liu, Z.; Wang, W. Screening of ionic liquids to capture $\mathrm{CO}_{2}$ by COSMO-RS and experiments. AIChE J. 2008, 54, 2717-2728. [CrossRef]

26. Maiti, A. Theoretical screening of ionic liquid solvents for carbon capture. ChemSusChem 2009, 2, 628-631. [CrossRef] [PubMed] 
27. Palomar, J.; Gonzalez-Miquel, M.; Polo, A.; Rodriguez, F. Understanding the physical absorption of $\mathrm{CO}_{2}$ in ionic liquids using the cosmo-rs method. Ind. Eng. Chem. Res. 2011, 50, 3452-3463. [CrossRef]

28. Gonzalez-Miquel, M.; Palomar, J.; Omar, S.; Rodriguez, F. $\mathrm{CO}_{2} / \mathrm{N}_{2}$ selectivity prediction in supported ionic liquid membranes (silms) by cosmo-rs. Ind. Eng. Chem. Res. 2011, 50, 5739-5748. [CrossRef]

29. Lapkin, A.A.; Peters, M.; Greiner, L.; Chemat, S.; Leonhard, K.; Liauw, M.A.; Leitner, W. Screening of new solvents for artemisinin extraction process using ab initio methodology. Green Chem. 2010, 12, 241-251. [CrossRef]

30. Kahlen, J.; Masuch, K.; Leonhard, K. Modelling cellulose solubilities in ionic liquids using COSMO-RS. Green Chem. 2010, 12, 2172-2181. [CrossRef]

31. Klamt, A.; Eckert, F. Cosmo-rs: A novel and efficient method for the a priori prediction of thermophysical data of liquids. Fluid Phase Equilibria 2000, 172, 43-72. [CrossRef]

32. Eckert, F.; Klamt, A. COSMOtherm, Version C2.1; COSMOlogic GmbH \& Co. KG: Leverkusen, Germany, 2009.

33. Ahlrichs, R.; Bär, M.; Häser, M.; Horn, H.; Kölmel, C. Electronic structure calculations on workstation computers: The program system turbomole. Chem. Phys. Lett. 1989, 162, 165-169. [CrossRef]

34. Schäfer, A.; Huber, C.; Ahlrichs, R. Fully optimized contracted gaussian basis sets of triple zeta valence quality for atoms li to kr. J. Chem. Phys. 1994, 100, 5829-5835. [CrossRef]

35. Becke, A.D. Density-functional exchange-energy approximation with correct asymptotic behavior. Phys. Rev. A 1988, 38, 3098-3100. [CrossRef] [PubMed]

36. Perdew, J.P. Density-functional approximation for the correlation energy of the inhomogeneous electron gas. Phys. Rev. B 1986, 33, 8822-8824. [CrossRef] [PubMed]

37. Sumon, K.Z.; Henni, A. Ionic liquids for $\mathrm{CO}_{2}$ capture using COSMO-RS: Effect of structure, properties and molecular interactions on solubility and selectivity. Fluid Phase Equilibria 2011, 310, 39-55. [CrossRef]

38. Akhmetshina, A.I.; Petukhov, A.N.; Vorotyntsev, A.V.; Nyuchev, A.V.; Vorotyntsev, I.V. Absorption Behavior of Acid Gases in Protic Ionic Liquid/Alkanolamine Binary Mixtures. ACS Sustain. Chem. Eng. 2017, 5, 3429-3437. [CrossRef]

39. Huang, K.; Cai, D.-N.; Chen, Y.-L.; Wu, Y.-T.; Hu, X.-B.; Zhang, Z.-B. Thermodynamic validation of 1-alkyl-3-methylimidazolium carboxylates as task-specific ionic liquids for $\mathrm{H}_{2} \mathrm{~S}$ absorption. AIChE J. 2013, 59, 2227-2235. [CrossRef]

40. Husson-Borg, P.; Majer, V.; Costa Gomes, M.F. Solubilities of oxygen and carbon dioxide in butyl methyl imidazolium tetrafluoroborate as a function of temperature and at pressures close to atmospheric pressure. J. Chem. Eng. Data 2003, 48, 480-485. [CrossRef]

41. Camper, D.; Bara, J.; Koval, C.; Noble, R. Bulk-fluid solubility and membrane feasibility of rmim-based room-temperature ionic liquids. Ind. Eng. Chem. Res. 2006, 45, 6279-6283. [CrossRef]

42. Shannon, M.S.; Tedstone, J.M.; Danielsen, S.P.O.; Hindman, M.S.; Irvin, A.C.; Bara, J.E. Free volume as the basis of gas solubility and selectivity in imidazolium-based ionic liquids. Ind. Eng. Chem. Res. 2012, 51, 5565-5576. [CrossRef]

Publisher's Note: MDPI stays neutral with regard to jurisdictional claims in published maps and institutional affiliations.

(C) 2020 by the authors. Licensee MDPI, Basel, Switzerland. This article is an open access article distributed under the terms and conditions of the Creative Commons Attribution (CC BY) license (http://creativecommons.org/licenses/by/4.0/). 